CrossMark \& click for updates

Cite this: Phys. Chem. Chem. Phys., $2016,18,24437$

Received 23rd June 2016, Accepted 1st August 2016

DOI: $10.1039 / c 6 c p 04421 b$

www.rsc.org/pccp

\title{
From bulk to plasmonic nanoparticle surfaces: the behavior of two potent therapeutic peptides, octreotide and pasireotide $\dagger$
}

\author{
Belén Hernández, ${ }^{a}$ Eduardo López-Tobar, ${ }^{b}$ Santiago Sanchez-Cortes, ${ }^{b}$ \\ Yves-Marie Coïc, ${ }^{c}$ Bruno Baron, ${ }^{d}$ Alexandre Chenal, ${ }^{\text {e }}$ Sergei G. Kruglik, ${ }^{\text {fg }}$ \\ Fernando Pflüger, ${ }^{a}$ Régis Cohen ${ }^{\text {h }}$ and Mahmoud Ghomi ${ }^{* a}$
}

\begin{abstract}
Octreotide and pasireotide are two cyclic somatostatin analogues with an important clinical use in the treatment and diagnosis of neuroendocrine tumors. Herein, by the combined use of several techniques (UV-visible absorption, fluorescence, circular dichroism, $\zeta$-potential, transmission electron microscopy, Raman scattering, surface-enhanced Raman scattering, and quantum mechanical calculations) we have followed the structural dynamics of these analogues in the bulk, as well as their binding sites on plasmonic (gold and silver) colloids. In contrast to the previously derived conclusions, the two peptides seem to possess completely different conformational features. Octreotide, a cyclic octapeptide, is formed by a moderately flexible type-II' $\beta$-turn maintained by a deformable disulfide linkage. Pasireotide, in which the cyclic character is made possible by peptide bonds, manifests a rigid backbone formed by two oppositely placed tight turns of different types, i.e. $\gamma$-turn and type-I $\beta$-turn. Owing to their cationic character, both analogues induce aggregation of negatively charged gold and silver colloids. Nevertheless, despite their notable structural differences, both peptides bind onto gold nanoparticles through their unique D-Trp residue. In contrast, their binding to silver colloids seems to be of electrostatic nature, as formed through monodentate or bidentate ionic pairs.
\end{abstract}

\section{Introduction}

Since its discovery in 1973, many functional roles have been attributed to the natural hormone somatostatin (SST). ${ }^{1}$ In mammals SST exists as a cyclic peptide in two biologically active isoforms, consisting of 14 (SST-14) and 28 (SST-28) amino

\footnotetext{
${ }^{a}$ Sorbonne Paris Cité, Université Paris 13, Groupe de Biophysique Moléculaire, UFR Santé-Médecine-Biologie Humaine, 74 Rue Marcel Cachin, 93017 Bobigny Cedex, France. E-mail: mahmoud.ghomi@univ-paris13.fr

${ }^{b}$ Instituto de Estructura de la Materia, IEM-CSIC, Serrano 121, 28006-Madrid, Spain

${ }^{c}$ Institut Pasteur, Unité de Chimie des Biomolécules, UMR 3523, 28 Rue du Docteur Roux, 75724 Paris Cedex 15, France

${ }^{d}$ Institut Pasteur, Plate-Forme de Biophysique de Macromolécules et de leurs Interactions, 25 Rue du Docteur Roux, 75724 Paris Cedex 15, France

${ }^{e}$ Institut Pasteur, Unité Biochimie des Interactions Macromoléculaires, UMR CNRS 3528, 25 Rue du Docteur Roux, 75724 Paris Cedex 15, France

${ }^{f}$ Sorbonne Universités, UPMC Univ. Paris 06, UMR 8237, Laboratoire Jean Perrin, 75005 Paris, France

${ }^{g}$ CNRS, UMR 8237, Laboratoire Jean-Perrin, 75005 Paris, France

${ }^{h}$ Service d'Endocrinologie, Centre Hospitalier de Saint-Denis,

2 Rue du Docteur Delafontaine, 93200 Saint-Denis, France

$\dagger$ Electronic supplementary information (ESI) available. See DOI: 10.1039/ c6сp04421b
}

acids (AAs), acting on five SST receptors (referred to as SSTR $i$, $i=1, \ldots, 5)$. Nonetheless, because of the short SST life-time in plasma ( $<3$ minutes), various synthetic analogues have been elaborated with important clinical use, particularly in the treatment and diagnosis of neuroendocrine tumors (NETS) of pituitary, parathyroid, pancreas and bronchi. Because of a good benefit/risk ratio, these molecules are currently used not only for their anti-secretory hormone properties but also in the control of growth of benign or malignant endocrine tumors. Here, we focus on two synthetic SST analogues (Scheme 1): (i) octreotide (SMS201-955), which is the first stable analogue available for clinical use with a high affinity for SSTR2 and a relatively high affinity for SSTR5; (ii) pasireotide (SOM230), a recently synthesized SST analogue, targeting four of the five SST receptors with the highest affinity for SSTR $5 .{ }^{2}$

The therapeutic effects of these two peptides are primarily related to their different amino acid sequences formed by natural and synthetic residues. As in the case of SST, the Trp-Lys pair plays a key role in the interaction of both analogues with SSTRs. ${ }^{3}$ However, since the earliest studies, ${ }^{4,5}$ the ${ }^{-}-\mathrm{D}$ replacement of the Trp residue was revealed to considerably enhance the biological activity of SST analogues. Octreotide contains two D-stereoisomers (D-Phe ${ }^{1}$ and $\left.{ }^{D}-T_{r p}^{4}\right)$ and a $\mathrm{C}^{\text {ter }}$ threoninol. 
A

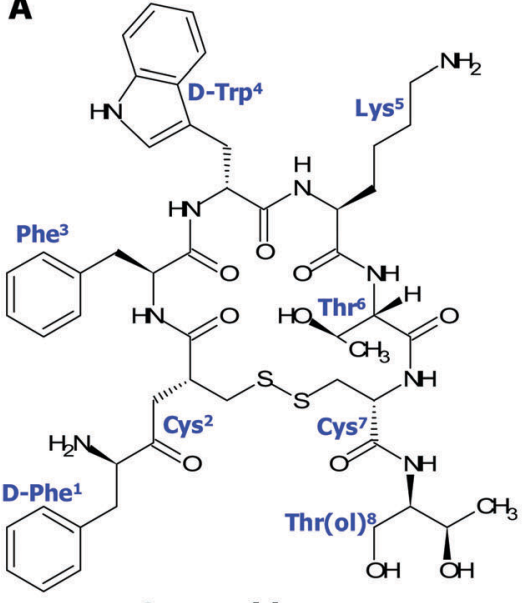

Octreotide
B

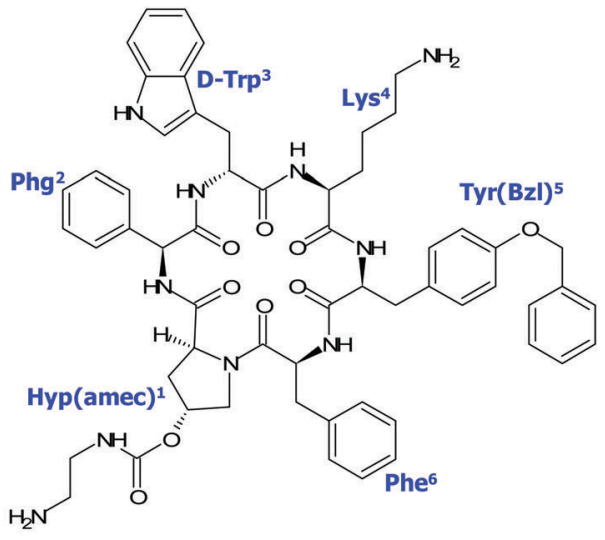

Pasireotide

$\operatorname{Thr}($ ol $)=$ Threoninol

Hyp(amec) = 2-aminoethyl-carbamoyl-Hydroxyproline Phg $=$ Phenylglycine $\operatorname{Tyr}(B z l)=0$-benzyl-Tyrosine

Scheme 1 Chemical composition and amino acid numbering of octreotide (A) and pasireotide (B).

Its cyclic structure is maintained by the $\mathrm{Cys}^{2}-\mathrm{Cys}^{7}$ disulfide linkage (Scheme 1A). The pasireotide backbone closure is rendered possible through peptide bonds (Scheme 1B). Hence, the definition of an $\mathrm{N}^{\text {ter }}-\mathrm{C}^{\text {ter }}$ path in its backbone is not straightforward. Nevertheless, to facilitate the comparison of the cyclic parts of the two peptides, we have adopted a previously suggested amino acid numbering for pasireotide. ${ }^{6}$ At last the presence of two long side chain amino acids, i.e. $\operatorname{Hyp}(\mathrm{amec})^{1}$ and $\operatorname{Tyr}(\mathrm{Bzl})^{5}$, should be particularly emphasized in pasireotide. Around physiological pH, both analogues are of cationic character, each one bearing two $\mathrm{NH}_{3}{ }^{+}$groups located in the $\mathrm{N}^{\text {ter }}$ and Lys $^{5}$ of octreotide, or in the Hyp(amec) $)^{1}$ and Lys $^{4}$ residues of pasireotide.

From the conformational point of view, the crystal and NMR data of octreotide, as well as its optical spectroscopic markers, ${ }^{7-10}$ have provided evidence for the presence of a type-II' $\beta$-turn formed around the central $-\mathrm{D}-\mathrm{Trp}^{4}-\mathrm{Lys}^{5}$ - residues. Comparatively, the available structural data of pasireotide are limited to the NMR-based ${ }^{11}$ molecular dynamics (MD) calculations $^{6}$ that had suggested similar conformational features for octreotide and pasireotide, fluctuating between flat and saddle-like backbone configurations. To our knowledge, no other structural investigation has provided insight into the conformational similarities of the two SST analogues.

During the last few decades, unique optical properties and facile surface chemistry of gold and silver (plasmonic) nanoparticles (NPs) have particularly motivated their use in biology and medicine through their possible applications in catalysis, biosensing, drug delivery, and plasmonic photothermal therapy (PPTT).${ }^{12-21}$ AuNPs were previously described as efficient tools for targeting cancer. ${ }^{14-16}$ Bioengineered silica-AuNPs were tested in diagnosis and treatment of atherosclerosis plaques. ${ }^{17}$ Likewise, coated NPs were employed in the case of coronary artery disease. ${ }^{18}$ It is worth emphasizing that the remarkable optical properties of plasmonic NPs, originating from the so-called localized surface plasmon resonance (LSPR) effect, are size- and shapedependent. ${ }^{12,13}$ These properties can be monitored by functionalization, ${ }^{19}$ allowing a better addressability of specific cellular/ tissular targets. For instance, liposomes containing adequately functionalized AuNPs have been used to discriminate between wild-type and mutant human tumor suppressor p53. ${ }^{16}$ In relation with the present work, recent investigations on tumor cell cultures incubated with functionalized AuNPs have revealed that: (i) the cellular uptake by means of SST-coated AuNPs performed on HCC-1806, HELA and U-87 cell lines is significantly higher than that achieved by nonfunctionalized gold particles; ${ }^{20}$ (ii) the temperature increase induced by a short time (5 ns) visible light $(532 \mathrm{~nm})$ irradiation in HELA cells incubated with octreotide-coated AuNPs leads to decreased cell viability. ${ }^{21}$

Herein, we have followed two complementary objectives. Our first aim was to get insight into the structural similarities/ differences of octreotide and pasireotide in an aqueous environment. In the second step, we have attempted to analyze the ability of these SST analogues to bind to the negatively charged gold and silver particles. In this framework, we have basically focused on the elucidation of the anchoring sites of these peptides, which cannot be easily addressed by the routine physical techniques. Obviously, the information collected on this point can be used in further studies on the elaboration of functionalized plasmonic NPs for diagnosis and therapeutic purposes. To achieve the above mentioned goals, a series of analytic and imaging techniques have been jointly used. Among them, surface enhanced Raman scattering (SERS), taking benefit from the LSPR effect, should be emphasized. In fact, the electromagnetic field of the incident and scattered light can be considerably enhanced upon NP aggregation, which gives rise to the formation of the so-called hot spots (narrow interparticle junctions). ${ }^{22,23}$ 
As a consequence, beyond the detection of the traces of molecular species in solution, SERS makes possible the identification of the specific molecular groups involved in their adsorption. ${ }^{22}$

\section{Results and discussion}

2.1. Backbone conformations of octreotide and pasireotide: evidence from CD spectra

Fig. 1A displays the CD spectra of octreotide and pasireotide recorded in water at $50 \mu \mathrm{M}$. These spectra have completely different shapes, as characterized by two deep minima at $\sim 202$ and $\sim 217 \mathrm{~nm}$ in octreotide, and a very deep minimum at $\sim 190 \mathrm{~nm}$ followed by three successive maxima at $\sim 202, \sim 213$ and $\sim 230 \mathrm{~nm}$ in pasireotide.

In a previous report, ${ }^{10}$ the $\mathrm{CD}$ fingerprint of octreotide was correlated with the type-II' $\beta$-turn formed on its four central residues $-\mathrm{Phe}^{3}-\mathrm{D}-\mathrm{Trp}^{4}-\mathrm{Lys}^{5}-\mathrm{Thr}^{6}-($ Scheme $1 \mathrm{~A})$. A $\beta$-turn represents a tight fold including four residues, referred to as $i$ to $i+3$, having special $\phi$ and $\psi$ values corresponding to the two middle $i+1$ and $i+2$ residues. ${ }^{24}$ Octreotide is certainly the only SST analogue, the crystal structure of which has been resolved, ${ }^{25}$ showing three molecules (referred to by the numbers I, II and III) in the asymmetric unit. All three molecules are characterized by a central type-II' $\beta$-turn. While molecule I has a regular flat antiparallel $\beta$-sheet structure, the other two (molecules II and III) present a distortion at their C-terminal part, favoring $\mathrm{H}$-bonding with surrounding water molecules. NMR data proved the presence of similar conformers in aqueous media, with a possible interconversion between them. ${ }^{8,9}$ For the sake of brevity, two different views of a structural model close to molecule $\mathrm{I}^{26}$ are displayed in Fig. 2A and B. The stability of this structure is reinforced by two intramolecular $\mathrm{H}$-bonds between $\mathrm{Phe}^{3}$ and $\mathrm{Thr}^{6}$ residues, i.e. $\mathrm{C}=\mathrm{O}\left(\mathrm{Phe}^{3}\right) \cdots \mathrm{H}-\mathrm{N}\left(\mathrm{Thr}^{6}\right)$ and $\mathrm{N}-\mathrm{H}$ $\left(\mathrm{Phe}^{3}\right) \cdots \mathrm{O}=\mathrm{C}\left(\mathrm{Thr}^{6}\right.$ ) (Fig. 2A). See also Table 2 and Table S1 (ESI $\dagger$ ) for the backbone torsion angles $(\phi, \psi, \omega)$ and Cartesian coordinates of this structural model, respectively. Concerning the CD spectrum of octreotide (Fig. 1A), it should also be stressed that the ellipticity ratio, namely $\Phi_{2} / \Phi_{1}$ (where $\Phi_{2}$ and $\Phi_{1}$ refer to the ellipticities of the two minima at $\sim 217$ and $\sim 202 \mathrm{~nm}$, respectively), was shown to be related to the type-II $\beta$-turn stability. ${ }^{10,27}$ This ratio is nearly $\sim 0.75(>0.5)$ in octreotide, revealing a moderately stable $\beta$-turn.

In contrast, the CD spectrum of pasireotide (Fig. 1A) does not resemble any other characterized $\beta$-turn, such as those belonging to the type-I, -I' , -II, and -VIII. ${ }^{27-31}$ One may conclude that the particular pasireotide structure (different from that of octreotide) could be initiated by its proline ring containing residue, i.e. Hyp(amec) ${ }^{1}$. However, this cannot be considered as a pre-requisite because in another Pro containing cyclic hexapeptide, i.e. cyclo-(Phe-D-Pro-Gly-Arg-Gly-Asp), ${ }^{32}$ giving a CD fingerprint similar to that of octreotide (Fig. 1A), an interconversion, between the type-II' and -I' $\beta$-turn, was evidenced.

\subsection{Rotational freedom of $\mathrm{D}$-Trp residues: evidence from fluorescence spectra}

Fig. 1B and C display the fluorescence spectra of octreotide and pasireotide, respectively. They are dominated by the Trp emission, peaking at $\sim 350 \mathrm{~nm}$ in water, and progressively downshifted to $\sim 345 \mathrm{~nm}$ and $\sim 340 \mathrm{~nm}$ in the $\mathrm{H}_{2} \mathrm{O} / \mathrm{MeOH}$ mixture (50\%/50\%) and $\mathrm{MeOH}$, respectively. The normalized fluorescence
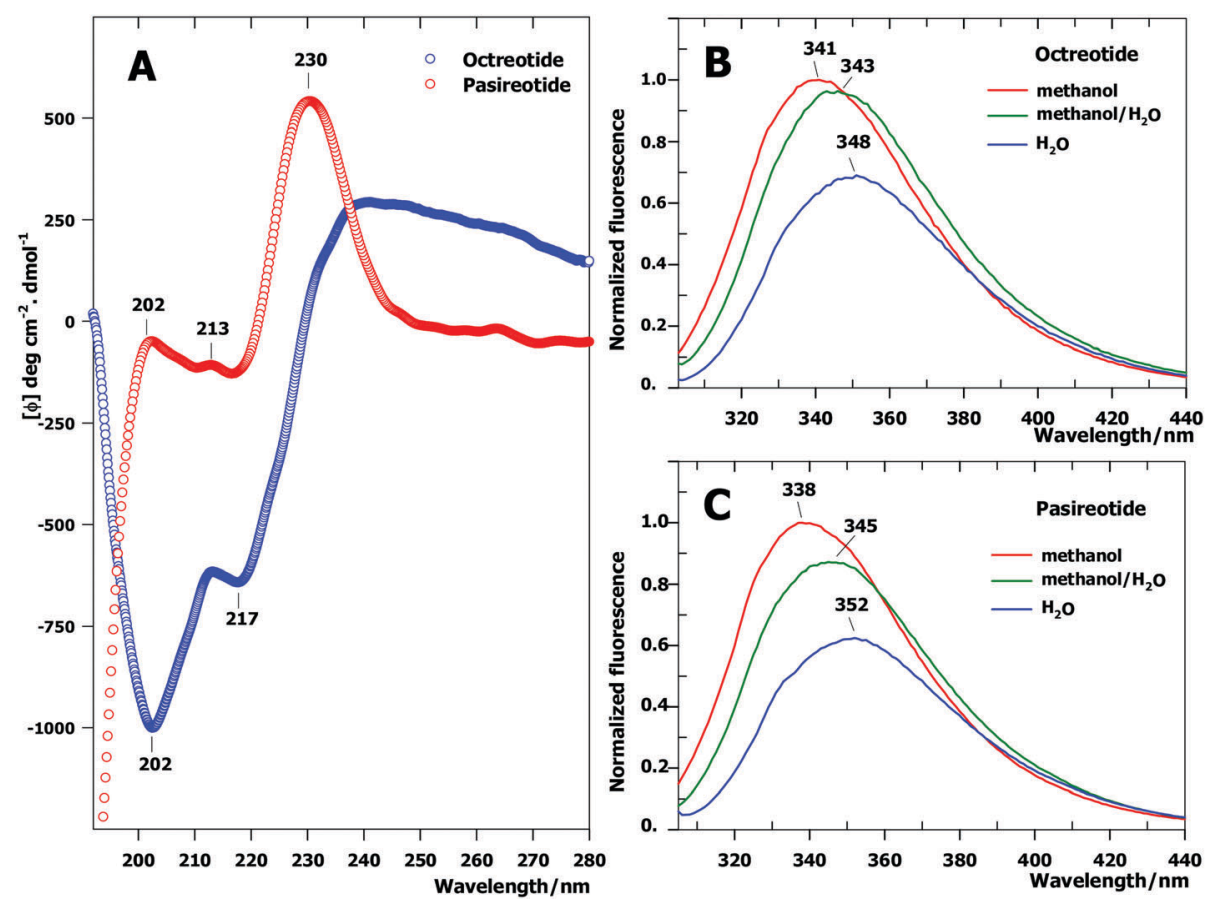

Fig. 1 Circular dichroism and fluorescence spectra of octreotide and pasireotide. (A) Room temperature CD spectra recorded at $50 \mu \mathrm{M}$. (B and C) Emission spectra of octreotide and pasireotide, respectively. Excitation wavelength: $290 \mathrm{~nm}$ and peptide concentration: $25 \mu \mathrm{M}$. Each color corresponds to a different buffer. 


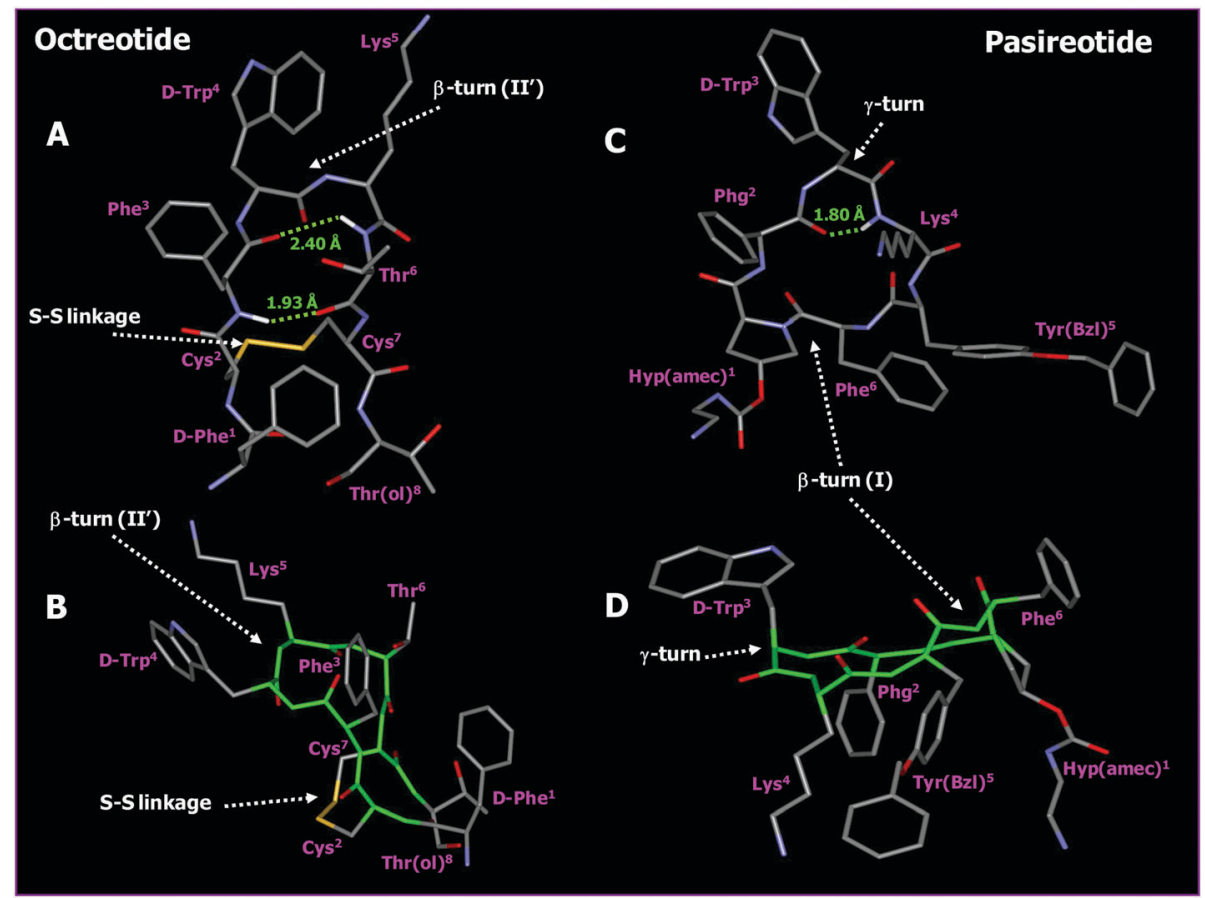

Fig. 2 Graphical representation of the structural models of octreotide ( $A$ and $B$ ) and pasireotide ( $C$ and $D)$. For the sake of clarity the hydrogen atoms are removed. In (B) and (D), the closed part of each peptide is presented in green color. Hydrogen bonds are displayed as broken green lines. See the text for details, Table 2 for backbone torsion angles, as well as Table S1 (ESI $\dagger$ ) for atomic Cartesian coordinates of these structural models.

spectrum is decreased by $\sim 35 \%$ in water, as compared to methanol, reflecting thereby the influence of the solvent polarity on the Trp emission spectrum. The anisotropy value, $\langle r\rangle$, was estimated to be $\sim 0$ in octreotide, and $\sim 0.02$ in pasireotide, indicating a high rotational freedom of the unique $\mathrm{D}$-Trp residue involved in each peptide. This value was found to be barely dependent on the peptide environment (water, methanol, and $\mathrm{NaCl}$ ).

\subsection{Backbone flexibility: evidence from bulk Raman spectra}

The quality of the Raman data recorded in aqueous solutions, as well as the low buffer contribution, plays a key role in obtaining accurate information on the structural features of a peptide chain by means of vibrational markers. To give an example, we have displayed in Fig. 3A the Raman spectra obtained from a solution sample containing octreotide, as compared with its solvent (water) spectrum. It can be seen that the whole middle wavenumber spectral region can be accurately analyzed without any interference with solvent contribution. For the sake of brevity, the buffer-subtracted Raman spectra of octreotide and pasireotide are compared in Fig. S1 ( $\mathrm{ESI} \dagger$ ). We focus on the Raman spectra observed in amide I (1700-1640 $\left.\mathrm{cm}^{-1}\right)$ and amide III (1305-1230 $\mathrm{cm}^{-1}$ ) regions (Fig. 3B and C), both providing valuable information on the secondary structure. ${ }^{10,27}$ It is worth pointing out that for each peptide, the structural analysis in both regions leads to similar results, as proved by the weights of secondary structural elements ( $\beta$-turn, $\beta$-strand, and random chain) displayed in Table 1 . Furthermore, pasireotide presents no clear trend to adopt an unordered (random) chain, simply because of the absence of the components at $\sim 1690 \mathrm{~cm}^{-1}$ (amide I) and $\sim 1265 \mathrm{~cm}^{-1}$ (amide III). This confers a rigid structure to the pasireotide backbone. In contrast, the weight of random chain in octreotide is estimated to be as high as $\sim 20 \%$, consistent with its backbone and disulfide linkage flexibility. A previous detailed report on the Raman data of octreotide ${ }^{10}$ has revealed two bands at $\sim 506$ and $\sim 520 \mathrm{~cm}^{-1}$ in the $\nu(\mathrm{S}-\mathrm{S})$ region (where $\nu$ denotes a bond-stretch vibrational motion), confirming the internal dynamics of the disulfide linkage (see also Fig. S1, $\mathrm{ESI} \dagger)$. It should be recalled that several rotamers can be defined around the $-\mathrm{C}_{\alpha}-\mathrm{C}_{\beta}-\mathrm{S}-\mathrm{S}-\mathrm{C}_{\beta^{\prime}}-\mathrm{C}_{\alpha^{\prime}}$ - segment, as governed by the corresponding five torsion angles $\left(\chi_{1}, \chi_{2}, \chi_{3}, \chi_{2}{ }^{\prime}, \chi_{1}{ }^{\prime}\right) .{ }^{29}$ In this framework, the structural model of octreotide displayed in Fig. 2A, corresponding to a disulfide rotamer characterized by the torsion angles $\left(-166^{\circ},+73^{\circ},-97^{\circ},+111^{\circ},-179^{\circ}\right)$, adopts the so-called -LHStaple (meaning "Left-Handed Staple-like S-S linkage with negative $\chi_{1}$ and $\chi_{1}{ }^{\prime}$ angles"). ${ }^{33}$ DFT calculations on cystine have evidenced that this rotamer can be responsible for the major $\nu(\mathrm{S}-\mathrm{S})$ Raman marker observed at $\sim 506 \mathrm{~cm}^{-1}$ in octreotide. ${ }^{33}$ It has also been shown that other disulfide rotamers, such as +RHHook ("Right-Handed Hook-like S-S linkage with positive $\chi_{1}$ and $\chi_{1}^{\prime}$ angles"), and \pm LHSpiral ("Left-Handed Spiral-like S-S linkage with opposite sign $\chi_{1}$ and $\chi_{1}{ }^{\prime}$ angles”) would be required to interpret the minor $\nu(\mathrm{S}-\mathrm{S})$ component at $\sim 520 \mathrm{~cm}^{-1}$ in octreotide. ${ }^{33}$

\subsection{Evidence on $\gamma$-turn in pasireotide}

As described above, the structure of pasireotide must be conformationally rigid, and cannot be simply represented by a direct or reverse $\beta$-turn. As a consequence, the previously proposed structural model of this hexapeptide, ${ }^{6}$ constructed upon its 

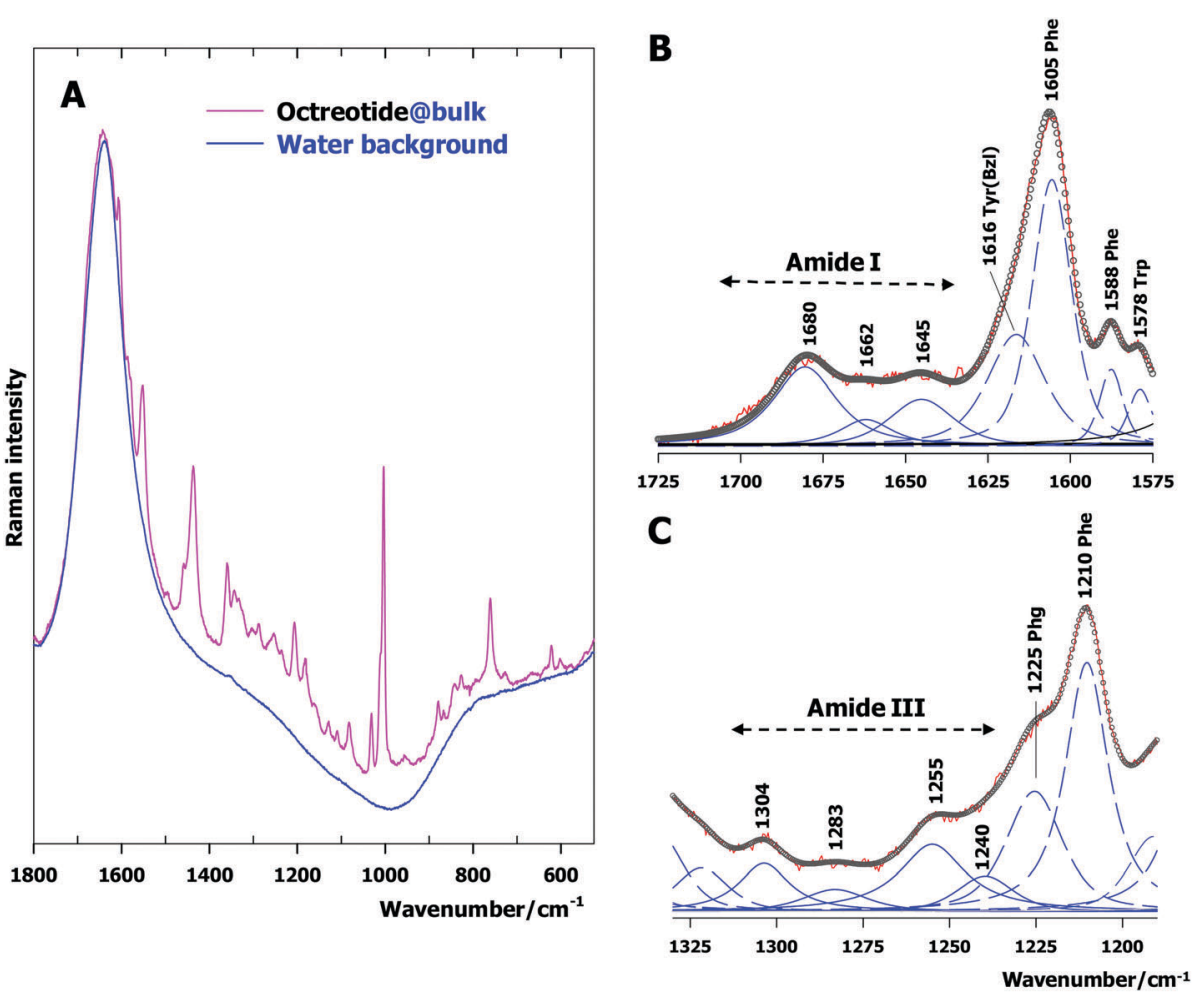

Fig. 3 Room temperature Raman spectra of octreotide and pasireotide recorded in aqueous solution. Excitation wavelength: $488 \mathrm{~nm}$. (A) Middle wavenumber spectral region of the Raman spectra recorded for the solutions containing octreotide (pink), and from water (blue). Raman spectra of pasireotide observed in the spectral regions including amide I (B) and amide III (C) vibrations. Components found by band decomposition in each spectral region are drawn as broken blue lines. Circles correspond to the sum of components.

Table 1 Secondary structural elements and their weights as determined by band decomposition of Raman spectra in amide I and amide III regions

\begin{tabular}{|c|c|c|c|}
\hline & Octreotide $^{a}$ & Pasireotide $^{b}$ & \\
\hline Spectral region & $\begin{array}{l}\text { Component } \\
\text { (weight\%) }\end{array}$ & $\begin{array}{l}\text { Component } \\
\text { (weight\%) }\end{array}$ & $\begin{array}{l}\text { Secondary } \\
\text { structure }\end{array}$ \\
\hline \multirow[t]{4}{*}{ Amide I } & $1692(13)$ & - & Random \\
\hline & $1678(46)$ & $1680(54)$ & Turn \\
\hline & $1663(23)$ & $1662(16)$ & $\beta$-Strand \\
\hline & 1650 (18) & $1645(30)$ & Turn \\
\hline$\Sigma$ random & 13 & 0 & \\
\hline$\Sigma$ turn & 64 & 84 & \\
\hline$\Sigma \beta$-strand & 23 & 16 & \\
\hline \multirow[t]{5}{*}{ Amide III } & $1302(14)$ & $1304(25)$ & Turn \\
\hline & $1288(21)$ & 1283 (13) & Turn \\
\hline & 1264 (14) & - & Random \\
\hline & $1251(31)$ & $1255(45)$ & Turn \\
\hline & $1235(20)$ & $1240(17)$ & $\beta$-Strand \\
\hline$\Sigma$ random & 14 & 0 & \\
\hline$\Sigma$ turn & 66 & 83 & \\
\hline$\Sigma \beta$-strand & 20 & 17 & \\
\hline
\end{tabular}

Component positions are reported in $\mathrm{cm}^{-1}$. In parentheses the weight of each component is given. $\Sigma$ designates the total weight corresponding to a given secondary structural element. ${ }^{a}$ Values taken from ref. 10. ${ }^{b}$ Present work. See also Fig. 3B and C.

possible structural similarities with octreotide, becomes inappropriate to interpret the presently reported data. To search an acceptable structural model for pasireotide, we have undertaken a series of experimental and theoretical analyses. Although the details of this study exceed the limits of the present discussion, we only mention here the main steps of our investigations:

(i) We have taken into account a previous challenging structural investigation, ${ }^{34}$ showing that despite their short length, tripeptides can be structured in an aqueous environment. For instance, the CD fingerprint of Ala-Phe-Ala presented a general shape completely different from that usually expected from an unordered chain. Precisely, this CD signature is composed of a deep minimum around $190 \mathrm{~nm}$, followed by two broad positive bands at higher wavelengths. NMR, FT-IR and classical MD data have provided additional information on the presence of a $\gamma$-turn around the central Phe residue of this tripeptide. ${ }^{34}$ It is to be noted that a $\gamma$-turn corresponds to a tight fold based on three residues, referred to as $i, i+1$ and $i+2$, in which $\phi$ and $\psi$ angles of the middle residue $(i+1)$ adopt special values. ${ }^{35}$ Two types of $\gamma$-turns can be encountered, referred to as classic and reverse $\gamma$-turn, one being the mirror image of the other. The resemblance between the CD signature of Ala-Phe-Ala and that of pasireotide (Fig. 1A) encouraged us to initiate a detailed analysis on the tripeptides, particularly those with the generic sequence Gly-Xxx-Gly (where Xxx = Phe, Tyr, Trp). It should be remarked that most of the recorded CD spectra contain at least a positive band at $\sim 225 \mathrm{~nm}$, presenting an additional maximum around $\sim 202 \mathrm{~nm}$, and a deep negative band at $\sim 190 \mathrm{~nm}$. Other $\gamma$-turn spectroscopic markers have been previously discussed by means of the Raman spectra obtained from antifreeze glycopeptides with a repeat tripeptide unit (Ala-Thr-Ala). ${ }^{36}$ 
The characteristic $\gamma$-turn amide I markers of these glycopeptides are quite close to those observed in pasireotide (Table 1).

(ii) In parallel to the experimental studies on $\gamma$-turn, we resorted to the DFT-based structural calculations, which could first confirm the stability of a classic and/or reverse $\gamma$-turn in tripeptides. We have then attempted to analyze pasireotide structural models. Because of the large number of atoms (144) involved in pasireotide, we could efficiently shorten the computational time through the consideration of a simple model compound, consisting of an all-Ala hexapeptide, in which only a Pro ring and a D-Ala, mimicking $\operatorname{Hyp}(\operatorname{amec})^{1}$ and ${ }^{D}-\operatorname{Trp}^{3}$ residues (Scheme 1B), respectively, were introduced. Several initial conformers of this model compound were geometry optimized. Among the most energetically favorable conformers, that involving a reverse $\gamma$-turn, formed around its D-Ala residue, regained our attention. We have then introduced one by one the side chains of the residues involved in pasireotide to the backbone, and followed the geometry optimization at each step. Two different views of the final geometry are displayed in Fig. 2C and D. Table 2 and Fig. S1 (ESI $\dagger$ ) show the backbone torsion angles $(\phi, \psi, \omega)$ and Cartesian coordinates of the suggested structural model, respectively. It is worth mentioning that this model is composed of two opposite tight folds, the first one is a reverse $\gamma$-turn based on the three residues $-\mathrm{Phg}^{2}{ }^{2} \mathrm{D}-\mathrm{Trp}^{3}-\mathrm{Lys}^{4}{ }^{4}$, while the second one is a type-I $\beta$-turn located on the four residues $-\operatorname{Tyr}(\mathrm{Bzl})^{5}-\mathrm{Phe}^{6}-\mathrm{Hyp}(\mathrm{amec})^{1}-\mathrm{Phg}^{2}-($ Fig. $2 \mathrm{C}$ and $\mathrm{D}$, Table 2). Note that the two $\beta$ - and $\gamma$-turns share the $\mathrm{Phg}^{2}$ residue at one of their extremities, and the whole backbone structure is stabilized by a short intramolecular $\mathrm{H}$-bond between the backbone $\mathrm{C}=\mathrm{O}\left(\mathrm{Phg}^{2}\right)$ and $\mathrm{N}-\mathrm{H}\left(\mathrm{Lys}^{4}\right)$ bonds (Fig. 2C). The suggested model can provide an acceptable interpretation to the CD fingerprint of pasireotide (Fig. 1A), which is presumably deduced from the superposition of two signals, one arising from the $\gamma$-turn (generally characterized by the two maxima at $\sim 202$ and $\sim 230 \mathrm{~nm}){ }^{34}$ and the other from the type-I $\beta$-turn (giving rise to the maximum at $\sim 213 \mathrm{~nm}$ ). ${ }^{29}$ Both folds were previously shown to provide a deep minimum around $190 \mathrm{~nm} .^{29,34,37}$

Nevertheless, further MD simulations on the presently suggested pasireotide structural model would allow confirmation of its stability in an explicitly hydrated environment.

\subsection{Aggregation of plasmonic colloids by peptides: evidence from extinction spectra}

In a recent work, we have reported on the temporal evolution of the electrostatic and plasmonic features of the citrate-reduced gold colloids. ${ }^{38}$ It appeared that large size AuNPs $(\sim 95 \mathrm{~nm})$, such as those used in the present study, can be considered as optimal SERS substrates for cationic peptides. In addition, the $\zeta$-potential value of these AuNPs, followed for a quite long period ( 3 months), was estimated to be found in the $\zeta=-26 \pm 6 \mathrm{mV}$ interval. ${ }^{38}$ In parallel, additional measurements on the AgNPs used in this work confirmed their high electrostatic and plasmonic robustness, as highlighted by the constancy of their $\zeta$-potential value $(\zeta=-41 \pm 1 \mathrm{mV})$, determined for a 2-month period. As a consequence, the negatively charged gold and silver
Table 2 Backbone torsion angles of octreotide and pasireotide

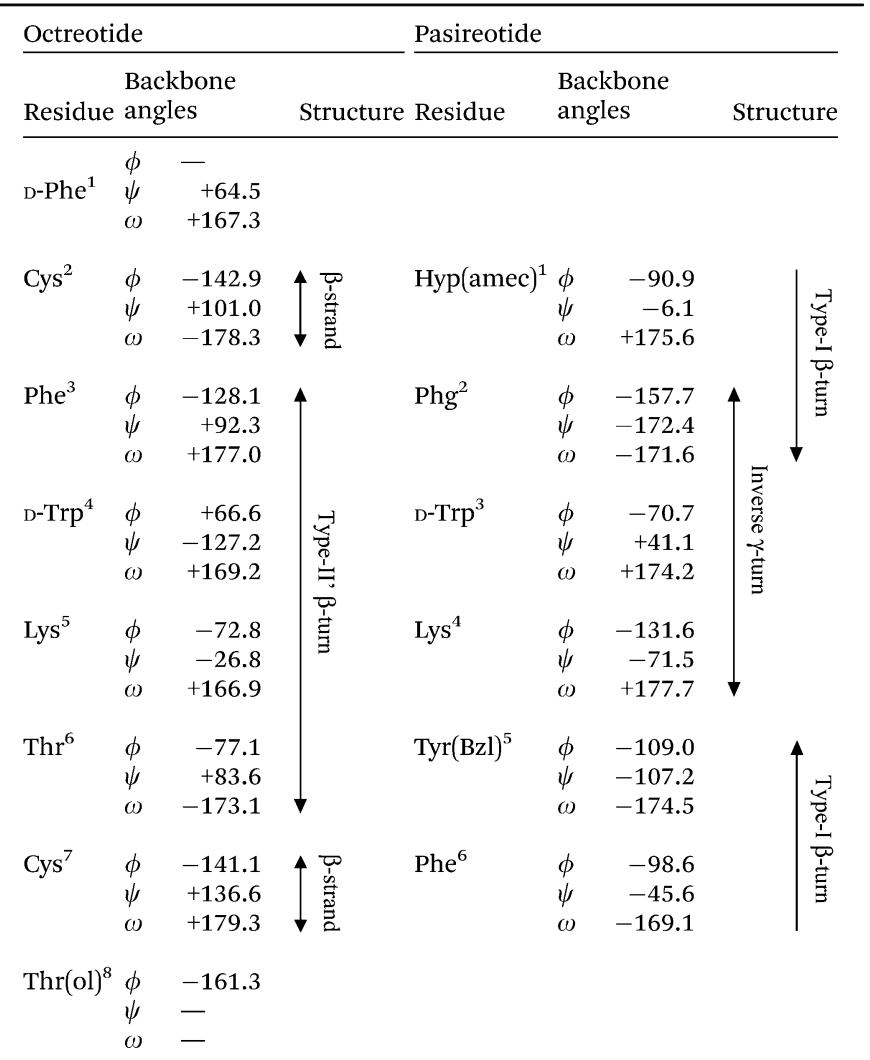

Torsion angles are expressed in degrees. For residue numbering, see also Scheme 1. Octreotide backbone angles are those from ref. 14. See Fig. 2A for graphical representation. Pasireotide backbone angles are those obtained by theoretical (DFT) calculations. See the text for details and Fig. 2B for graphical representation.

plasmonic surfaces could be considered as suitable substrates for the positively charged SST analogues. ${ }^{39}$

The aggregation of plasmonic particles, brought about by cationic peptides, was followed by UV-visible absorption spectra and TEM images (Fig. 4 and 5). In fact, the plasmonic redshift observed in the extinction spectra of AuNPs (Fig. 4A) and AgNPs (Fig. 5A) is the first indicator of NP aggregation. The optimal peptide concentration is that corresponding to the largest plasmonic redshift. This could be achieved at $10^{-7} \mathrm{M}$ for both peptides adsorbed on AuNPs (Fig. 4A). Higher concentrations, such as $10^{-6} \mathrm{M}$ for pasireotide and $10^{-5} \mathrm{M}$ for octreotide, were necessary to induce the largest plasmonic redshift of AgNPs (Fig. 5A). At these concentrations, TEM images also proved the formation of large size aggregates of gold (Fig. 4B and C) and silver (Fig. 5B and C) colloids.

\subsection{Characteristic aromatic Raman markers used to probe $\mathrm{NP} /$ peptide interactions}

The selected excitation wavelength, $\lambda_{\text {exc }}=785 \mathrm{~nm}$, for recording SERS falls inside the redshifted plasmonic band (Fig. 4A and 5A). SERS of the peptides recorded in the whole middle wavenumber spectral region is reported in Fig. S2 and S3 (ESI $\dagger$ ) for gold and silver colloids, respectively. In the main text, we limit our discussion to the most characteristic spectral regions 

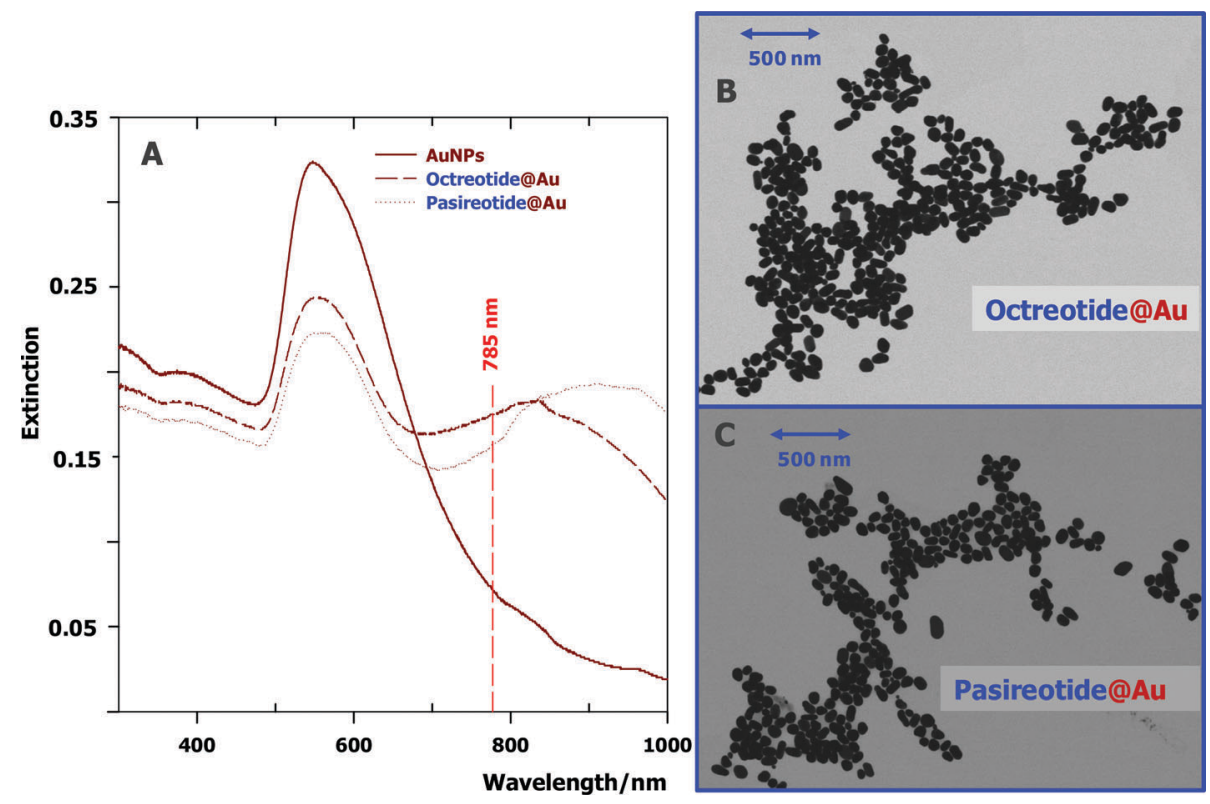

Fig. 4 Extinction spectra (A) and transmission electron microscopy images ( $B$ and $C$ ) of gold nanoparticles in the presence of octreotide and pasireotide. Peptide concentration at $10^{-7} \mathrm{M}$ for both peptides.
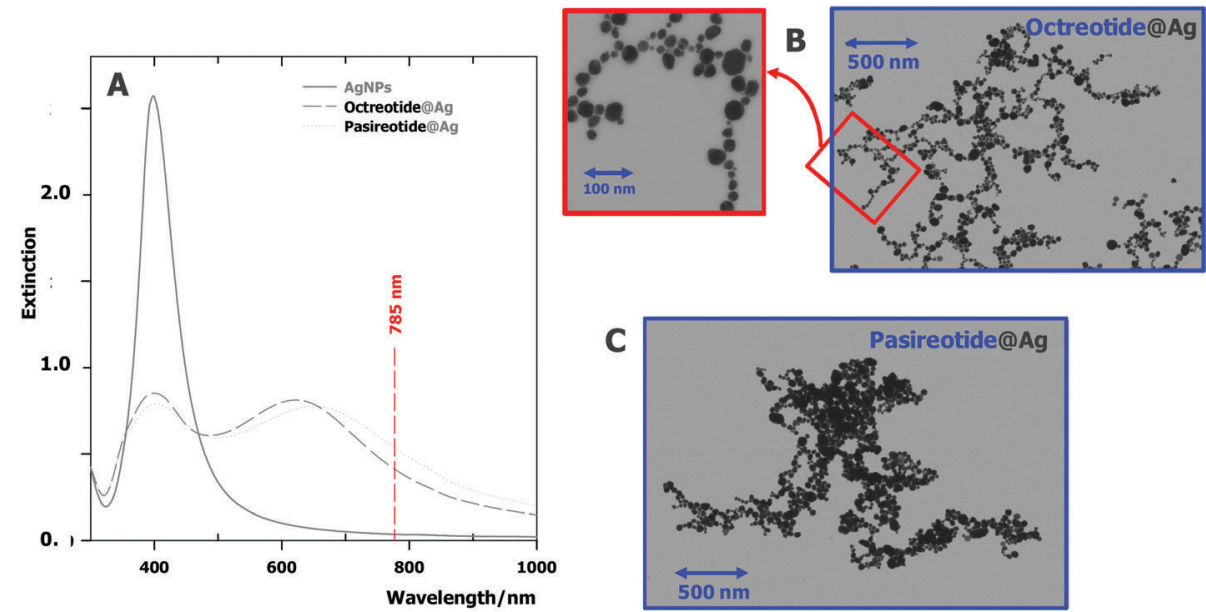

Fig. 5 Extinction spectra ( $A$ ) and transmission electron microscopy images ( $B$ and $C$ ) of silver nanoparticles in the presence of octreotide and pasireotide. Peptide concentration at: $10^{-5} \mathrm{M}$ for octreotide, and $10^{-6} \mathrm{M}$ for pasireotide.

(referred to as Region I-to-IV, see Fig. 6 and 7), involving the most characteristic aromatic markers. ${ }^{40-43}$ To facilitate the discussion, the bulk Raman spectra, as well as the tentative assignments of the most prominent observed bands, are also reported.

The SERS recorded on AgNPs (Fig. 6B and 7B) strikingly resembles that observed in the bulk (Fig. 6C and 7C). The wavenumber shifts in going from bulk to Ag surfaces do not exceed $5 \mathrm{~cm}^{-1}$. This fact indicates that although the aromatic residues remain close to the Ag surface, justifying thereby their high SERS intensities, they are not directly involved in the peptide adsorption. The situation is completely different in the case of AuNPs (Fig. 6A and 7A). While the Phe markers are barely affected by the peptide adsorption, considerable changes appear in Trp markers. One can notice for example (i) the $1551 \rightarrow 1527 \mathrm{~cm}^{-1}$ downshift (Region I); (ii) the doublet at 1360-1340 $\mathrm{cm}^{-1}$ merging to provide a unique band at $1356 \mathrm{~cm}^{-1}$ (Region II); (iii) the $\sim 1129 \rightarrow 1115 \mathrm{~cm}^{-1}$ downshift accompanied by an intensity enhancement (Region III); (iv) the vanishing of the shoulder at $\sim 1012 \mathrm{~cm}^{-1}$ (Region III); (v) the wavenumber shifts observed in three other markers, i.e. $880 \rightarrow 873 \mathrm{~cm}^{-1}$, $827 \rightarrow 843 \mathrm{~cm}^{-1}$, and $761 \rightarrow 755 \mathrm{~cm}^{-1}$ (Region IV).

It should be stressed that other aromatic ring containing residues, i.e. $\mathrm{Phg}^{2}$ and $\operatorname{Tyr}(\mathrm{Bzl})^{5}$, do not give rise to resolved and strong Raman (SERS) markers. This is basically due to the structural similarity of Phg (and the benzyl moiety of Tyr(Bzl)) to Phe, leading presumably to an overlap of their characteristic markers. However, band decomposition of the bulk Raman 
Octreotide

A

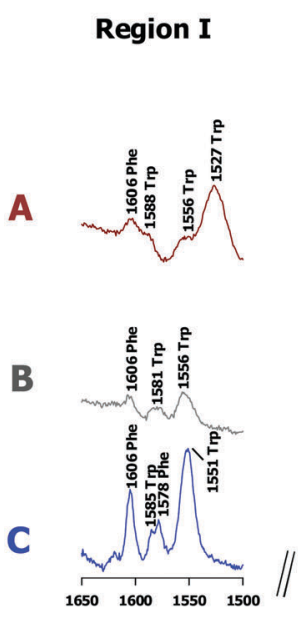

Region II
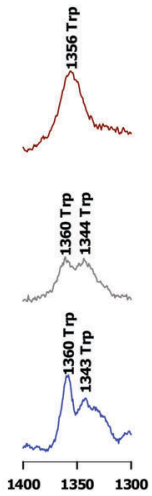

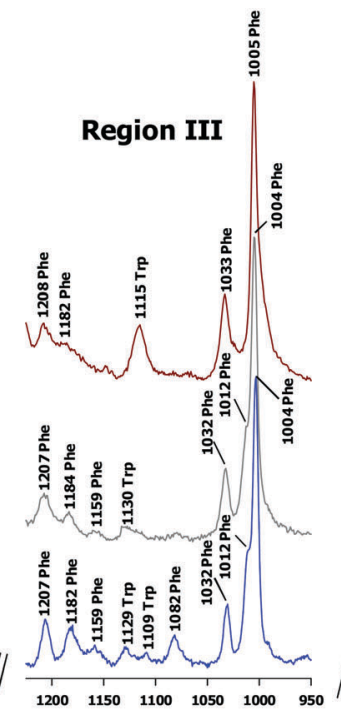

Region IV

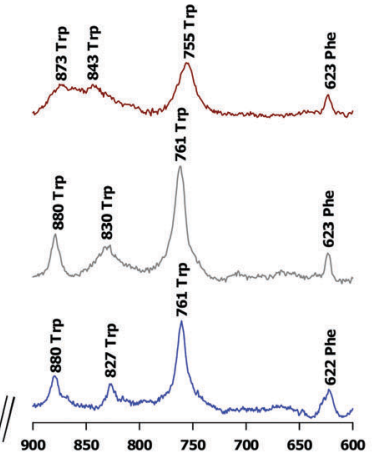

Wavenumber $/ \mathrm{cm}^{-1}$

Fig. 6 Focus on the four specific spectral regions (Regions I-to-IV) including the most characteristic aromatic markers. (A) SERS recorded from octreotide adsorbed on AuNPs $\left(10^{-7} \mathrm{M}\right)$, (B) SERS recorded from octreotide $\left(10^{-5} \mathrm{M}\right)$ adsorbed on AgNPs, and (C) Raman spectra recorded for the aqueous solutions containing octreotide $\left(5 \times 10^{-3} \mathrm{M}\right)$. Excitation wavelengths: $785 \mathrm{~nm}$ (SERS) and $488 \mathrm{~nm}$ (Raman in bulk).

\section{Pasireotide}

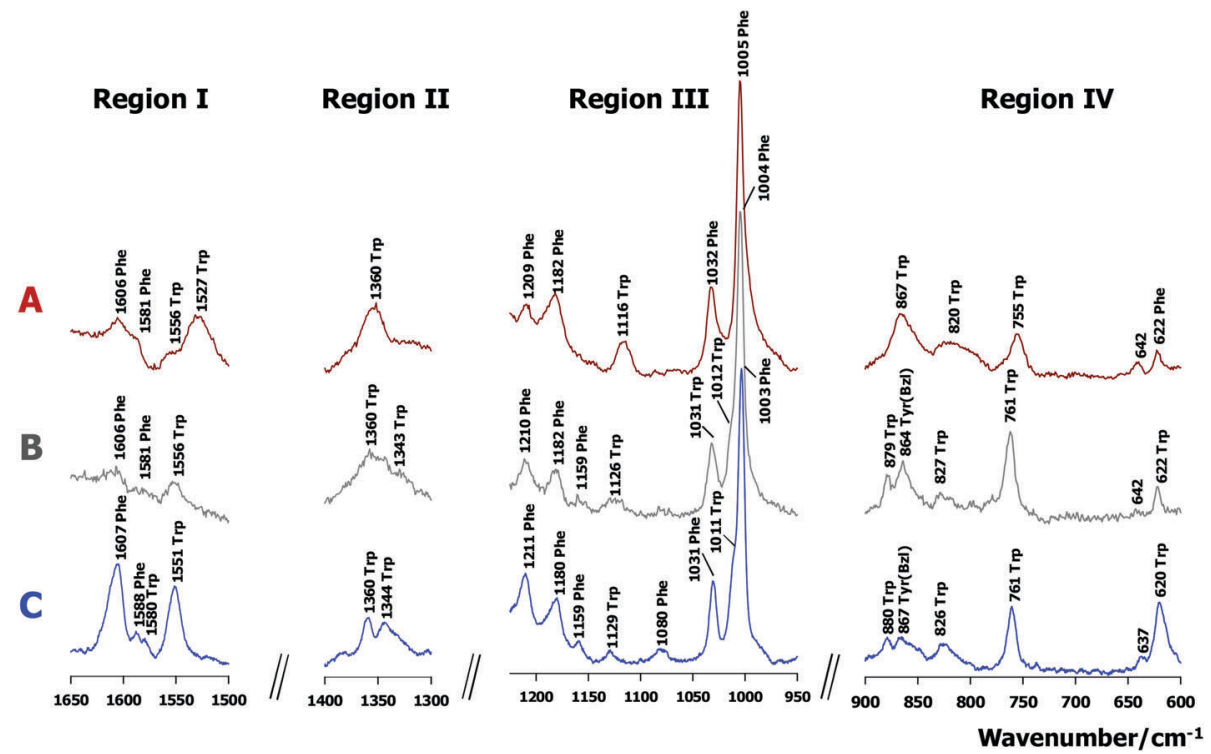

Fig. 7 Focus on the four specific spectral regions (Regions I-to-IV) including the most characteristic aromatic Raman markers. (A) SERS recorded from pasireotide adsorbed on AuNPs $\left(10^{-7} \mathrm{M}\right)$, (B) SERS recorded from pasireotide $\left(10^{-6} \mathrm{M}\right)$ adsorbed on AgNPs, and (C) Raman spectra recorded for the aqueous solutions containing octreotide $\left(2.5 \times 10^{-3} \mathrm{M}\right)$. Excitation wavelengths: $785 \mathrm{~nm}$ (SERS) and $488 \mathrm{~nm}$ (Raman in bulk).

spectra of pasireotide in the regions adjacent to amide I (Fig. 3B) and amide III (Fig. 3C) allows detection of two components at $\sim 1616$ and $\sim 1225 \mathrm{~cm}^{-1}$. While the former component, having a wavenumber close to that of a characteristic Tyr marker at $\sim 1616 \mathrm{~cm}^{-1},{ }^{39}$ can be assigned to the phenol ring of Tyr(Bzl) $)^{5}$, the latter, appearing as a shoulder on the characteristic Phe marker at $\sim 1210 \mathrm{~cm}^{-1},{ }^{42}$ might originate from the phenyl ring of $\mathrm{Phg}^{2}$. In Region IV of the bulk Raman spectrum of pasireotide (Fig. 6C), as well as in its SERS on AgNPs (Fig. 6B), the medium intensity Raman band observed at $\sim 867(864) \mathrm{cm}^{-1}$ can also be assigned to the phenol ring of $\operatorname{Tyr}(\mathrm{Bzl})^{5} .^{43}$

\subsection{Anchoring sites of octreotide and pasireotide on plasmonic nanoparticles}

Examination of the aromatic markers (Fig. 5 and 6) has clearly shown that the D-Trp is mostly affected by the adsorption of both peptides on AuNPs. To reinforce this conclusion, let us focus particularly on the $1050-975 \mathrm{~cm}^{-1}$ spectral region of all 
A

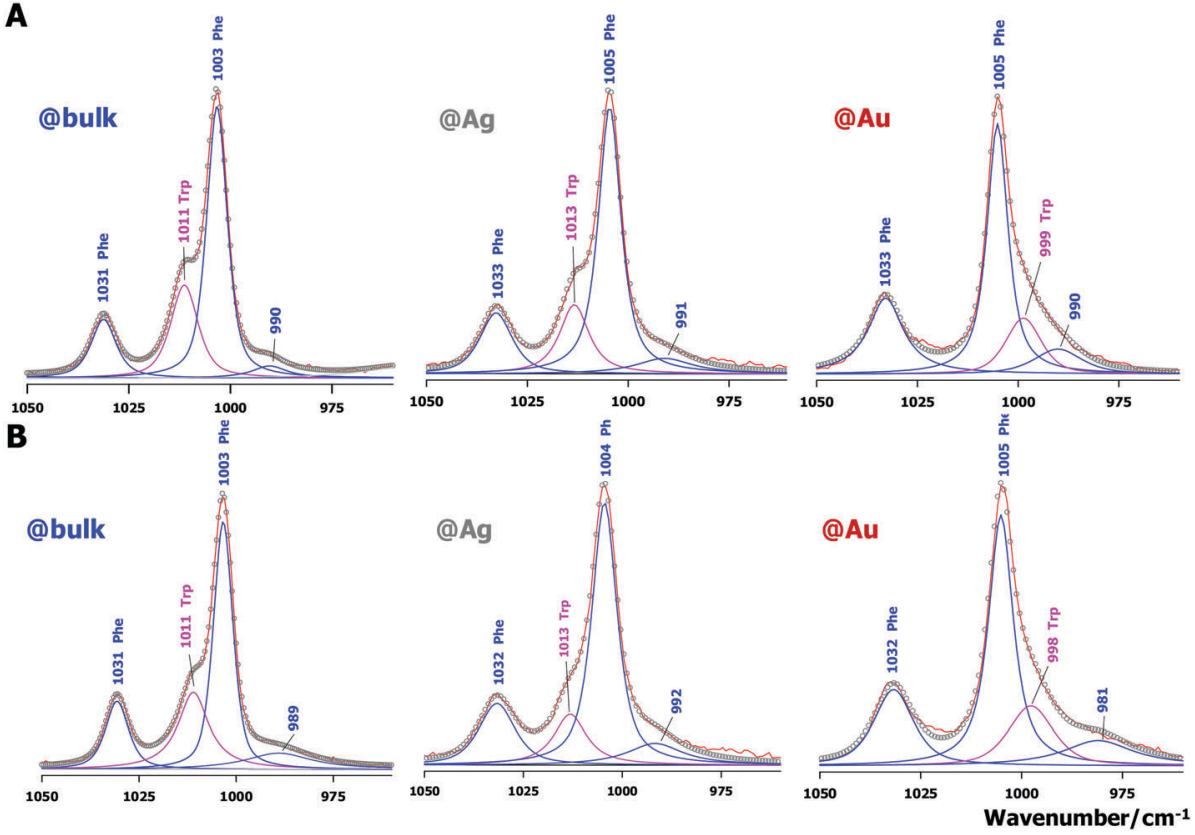

Fig. 8 Analysis by band decomposition of the Raman spectra of octreotide (A) and pasireotide (B) observed in the $1050-950 \mathrm{~cm}^{-1}$ spectral region. Left: Raman spectra corresponding to the solution containing each peptide, middle: SERS of each peptide adsorbed on AgNPs, and right: SERS of each peptide adsorbed on AuNPs.

Raman spectra (Fig. 8A and B). Band decomposition in this region reveals four components. Three of them arise from Phe, and only one is assignable to Trp. All the four components are barely affected in going from bulk to silver surfaces, whereas the Trp marker (observed at $\sim 1011 \mathrm{~cm}^{-1}$ in the bulk) undergoes a large downshift $\left(\sim 12 \mathrm{~cm}^{-1}\right)$ upon adsorption on AuNPs, leading to the apparition of a new component at $\sim 999 \mathrm{~cm}^{-1}$. Previous DFT calculations have assigned this Trp marker to an indole ring vibrational mode involving the displacements of the atoms close to $\mathrm{N}_{\varepsilon}{ }^{40}$ Another striking similar example concerns the intense Trp mode observed as a unique strong band at $\sim 1115 \mathrm{~cm}^{-1}$ upon adsorption of octreotide (Fig. 5A) and pasireotide (Fig. 6A) on AuNPs. This mode was also shown to involve the indole $\mathrm{N}_{\varepsilon}$ atom displacements. ${ }^{40}$ Based on these observations, one can confidently suggest that the binding of both SST analogues to AuNPs takes place through their unique D-Trp residue, presumably by the intermediate of the indole ring $\mathrm{N}_{\varepsilon}$ atom, as schematized in Fig. 9A and B.

In contrast, the adsorption of the peptides on AgNPs does not seem to directly involve aromatic residues. To collect more information on the possible binding sites, we resorted to the low wavenumber (300-175 $\mathrm{cm}^{-1}$ ) region (Fig. 10). In the absence of peptides, AgNPs provide a characteristic band at $\sim 245 \mathrm{~cm}^{-1}$ (Fig. 10A), assignable to the so-called $\nu\left(\mathrm{Ag}-\mathrm{Cl}^{-}\right)$vibrations. Upon adsorption of the peptides, an extra component at $\sim 220 \mathrm{~cm}^{-1}$ appears (Fig. 10B and C). To interpret this effect, we have to take into consideration a possible perturbation of $\nu\left(\mathrm{Ag}_{-}-\mathrm{Cl}^{-}\right)$vibration by the electrostatic interaction of a positively charged group $\left(\mathrm{NH}_{3}{ }^{+}\right)$of the peptide with a $\mathrm{Cl}^{-}$anion existing on the plasmonic surface. In the case of octreotide, the cationic groups, being located at two ultimate sides of the molecule, and oppositely oriented, favor two possible monodentate binding schemes through either the $\mathrm{N}^{\text {ter }}$ (Fig. 9C) or Lys ${ }^{5}$ end group (Fig. 9D). In pasireotide, the positively charged residues, Hyp(amec) ${ }^{1}$ and Lys $^{4}$, are rather oriented toward the same direction. Therefore, three possible binding schemes can be suggested. Two of them can be monodentate, involving only one of the two cationic $\left(\mathrm{NH}_{3}{ }^{+}\right)$groups (Fig. 9E and F), and the third one can be bidentate (Fig. 9G), taking place by the interaction of both cationic sites of the hexapeptide with the plasmonic surface.

\section{Materials and methods}

\subsection{Peptides}

Pasireotide was a gift from Novartis Pharma (Basel, Switzerland). The chemical synthesis of octreotide following the Fmoc/tBu methodology was reported in detail previously. ${ }^{10}$ Purity control of both peptides was performed by RP-HPLC. Respective masses of the peptides were determined by mass spectroscopy, as follows: octreotide $[\mathrm{M}+\mathrm{H}]^{+} 1019.45 \mathrm{~d}$, observed $1019.46 \mathrm{~d}$; pasireotide monoisotopic $[\mathrm{M}+\mathrm{H}]^{+} 1047.51 \mathrm{~d}$, observed $1047.73 \mathrm{~d}$. Aqueous samples of peptides were prepared by dissolving the lyophilized powder samples of the peptides in pure water obtained from a Millipore filtration system. Taking into account the low solubility of pasireotide, the maximum concentration, giving rise to a limpid solution, was $2.5 \mathrm{mM}$, i.e. $2.6 \mathrm{mg} \mathrm{mL}^{-1}$. This sample, serving as stock solution, was first used for classical Raman measurements in the bulk, and then further diluted for other experiments needing lower concentrations (fluorescence, CD and SERS). Stock solution of octreotide was prepared at $5 \mathrm{mM}$, i.e. $5.5 \mathrm{mg} \mathrm{mL}{ }^{-1}$, and then diluted. Additional fluorescence measurements were performed 


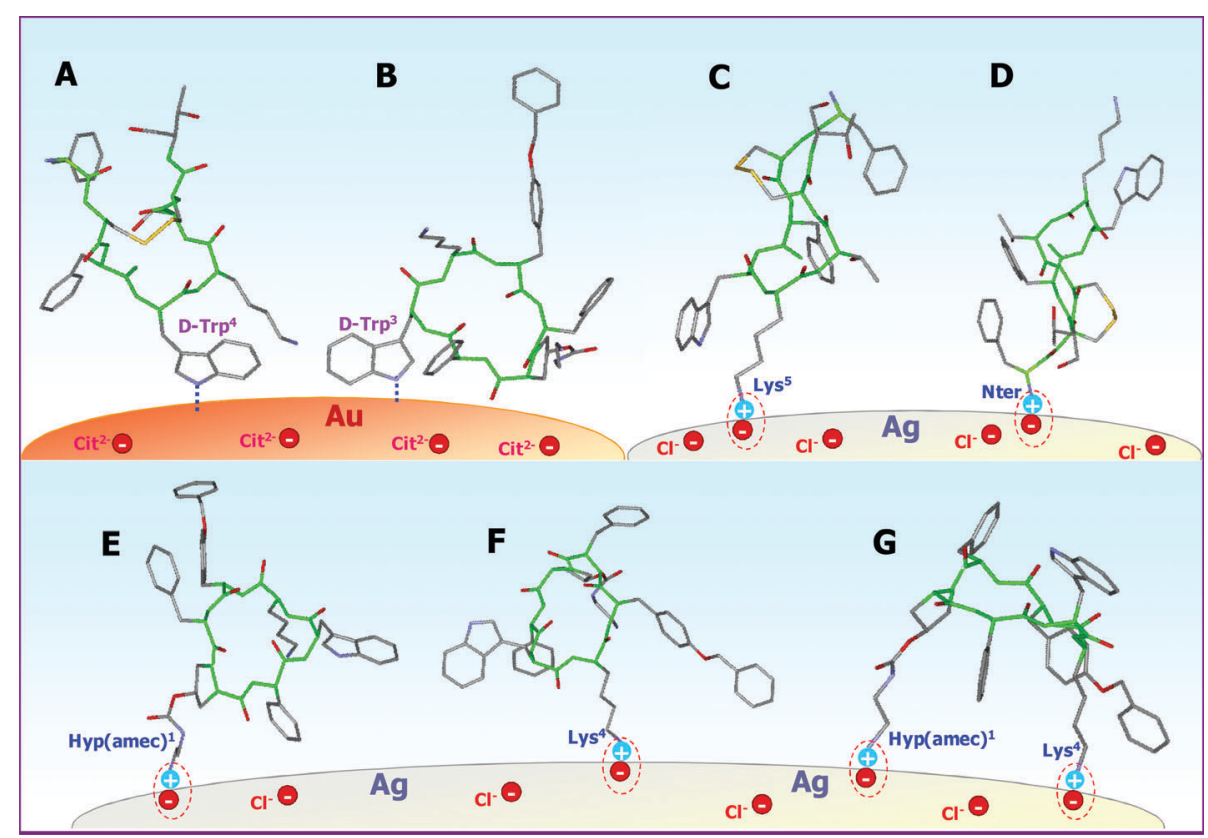

Fig. 9 Binding schemes of SST analogues on plasmonic nanoparticles. (A and B) Display the anchoring sites on AuNPs of octreotide and pasireotide, respectively. (C and D) Show the anchoring sites of octreotide on AgNPs. (E-G) Display different binding possibilities of pasireotide to AgNPs.
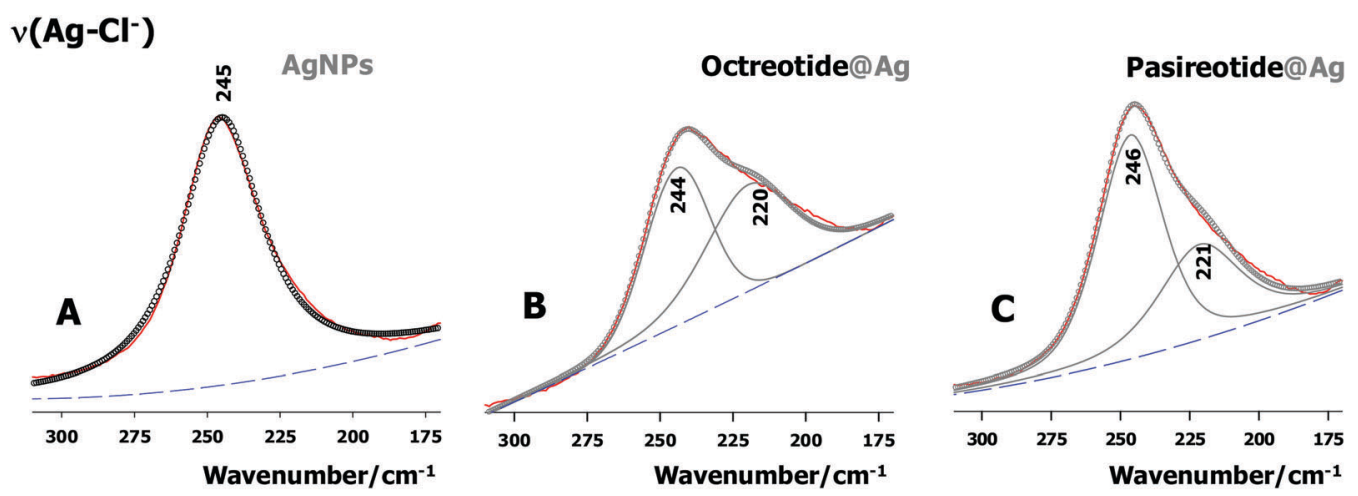

Fig. 10 Low wavenumber region of the SERS recorded from AgNPs (A), octreotide adsorbed on AgNPs (B), and pasireotide adsorbed on AgNPs (C).

on pasireotide in other solvents, such as $\mathrm{H}_{2} \mathrm{O} / \mathrm{MeOH}(50 \% / 50 \%)$ and $\mathrm{MeOH}$. Methanol was from Carlo Erba (ACS-ISO for analysis).

\subsection{Plasmonic nanoparticles}

$\mathrm{HAuCl}_{4}$, citrate $\cdot \mathrm{Na}_{3}, \mathrm{AgNO}_{3}, \mathrm{NaOH}$ and $\mathrm{NH}_{2} \mathrm{OH} \cdot \mathrm{HCl}$ were purchased from Sigma-Aldrich. Large size gold colloids $(\sim 95 \mathrm{~nm}$ particles) were prepared following the Turkevich-Frens method, ${ }^{44,45}$ upon addition of $0.16 \mathrm{~mL}$ of a citrate stock solution (1\% by weight) to a boiling solution of $\mathrm{HAuCl}_{4}\left(10^{-2} \%\right.$ by weight $)$. The mixture, turning to dark red, was cooled down to room temperature and kept at $4{ }^{\circ} \mathrm{C}$ for 7 days before use.

AgNP suspension was elaborated by adding $300 \mu \mathrm{L}$ of a sodium hydroxide solution $(1 \mathrm{M})$ to $90 \mathrm{~mL}$ of a $6 \times 10^{-2} \mathrm{M}$ hydroxylamine hydrochloride solution. Then $10 \mathrm{~mL}$ of a $1.11 \times$ $10^{-3}$ silver nitrate aqueous solution were added dropwise to the mixture under vigorous stirring. The solution containing silver colloids turned to brown; it was aged one week at $4{ }^{\circ} \mathrm{C}$ before use.
This preparation protocol gives generally rise to polydisperse silver colloids.

\subsection{Electrophoretic mobility and quasi-elastic light scattering}

The experiments were made at $25{ }^{\circ} \mathrm{C}$ on a NanozS instrument (Malvern Instrument Ltd, Malvern, UK) in DTS1060 cuvettes. The acceptable electrophoretic mobility $\left(\mu_{\mathrm{e}}\right)$ measurements were averaged and the standard deviation was computed. $\mu_{\mathrm{e}}$ was then converted to $\zeta$-potential. ${ }^{39,46,47}$ Quasi-elastic light scattering (QELS) experiments were performed before and after each measurement on $\mu_{\mathrm{e}}$, to follow size changes and to ensure that the samples were not affected by the applied voltage during the electrophoretic mobility experiment.

\subsection{Transmission electron microscopy}

TEM images were taken at room temperature using a JEOL JEM2010 with an acceleration voltage of $200 \mathrm{kV}$. The samples were 
prepared by depositing $10 \mu \mathrm{L}$ of the suspension containing plasmonic nanoparticles, or their complexes with the peptides on carbon coated $\mathrm{Cu}$ grids (ref. G400-Cu).

\subsection{Spectroscopic measurements}

UV-visible spectra of colloids were recorded at room temperature on a Shimadzu 3600 UV-visible absorption spectrometer by using quartz cells, and an optical path of $1 \mathrm{~cm}$.

Fluorescence spectra were recorded on a PTI Quanta-Master QM4CW spectrofluorometer (Lawrenceville, NJ) at $25{ }^{\circ} \mathrm{C}$ using a $10 \mathrm{~mm}$ pathlength quartz cell. Samples containing peptides were excited at $290 \mathrm{~nm}$. Excitation and emission bandwidths were set to 1 and $5 \mathrm{~nm}$, respectively. Corresponding values for anisotropy measurements were 5 and $15 \mathrm{~nm}$, respectively. Measurements by means of linearly polarized incident and emitted beams, parallel and perpendicular to the scattering plane, respectively, led us to estimate fluorescence anisotropy, $\langle r\rangle .{ }^{48}$

CD spectra were analyzed on a JASCO J-810 spectrophotometer within the 190-300 $\mathrm{nm}$ spectral region (path length: $1 \mathrm{~mm}$ and spectral resolution: $0.2 \mathrm{~nm}$ ). Each spectrum was recorded with a speed of $100 \mathrm{~nm} \mathrm{~min}{ }^{-1}$, and corresponds to an average of 5 scans. In order to facilitate the comparison of CD spectra, their normalized ellipticity was expressed in $\mathrm{deg} \mathrm{cm}^{2} \mathrm{dmol}^{-1}$.

Stokes Raman spectra were recorded at room temperature for the aqueous solutions of peptides (hereafter referred to as bulk Raman spectra) under the excitation at the $488 \mathrm{~nm}$ line emitted by an $\mathrm{Ar}^{+}$laser (Spectra Physics), and $200 \mathrm{~mW}$ power on the sample. Scattered light at right angles was analyzed on a Jobin-Yvon T64000 (single spectrograph configuration, 1200 grooves per mm holographic grating and a holographic notch filter). Raman data (1200 s acquisition time for each spectrum) were collected on a liquid nitrogen cooled CCD detection system (Spectrum One, Jobin-Yvon), and the effective spectral slit width was set to ca. $5 \mathrm{~cm}^{-1}$. GRAMS/32 software (Galactic Industries) was used for buffer subtraction and smoothing of observed spectra. The analysis of the composite spectral regions was performed by curve fitting using pseudo-Voigt (Gaussian + Lorentzian) functions, with the Lorentzian contribution kept equal to or greater than $50 \%$.

SERS data were collected on a Renishaw Raman InVia spectrometer equipped with an electrically cooled CCD camera. Samples containing plasmonic NPs to which the solution peptides at a given concentration were added were excited by means of the $785 \mathrm{~nm}$ line of a diode laser with an output power of $18 \mathrm{~mW}$ at the sample, and a 1200 grooves per $\mathrm{nm}$ holographic grating. The spectral resolution was $2 \mathrm{~cm}^{-1}$, with a total acquisition of 10 seconds for each SERS measurement.

\subsection{Quantum mechanical calculations}

Energetic and geometrical data of peptide conformers were estimated by the density functional theory (DFT) approach, ${ }^{49}$ using the Hybrid B3LYP functional. ${ }^{50,51}$ Taking into account the large number of atoms involved in the peptide conformers, polarized double-zeta Gaussian atomic basis sets, referred to as $6-31++G(d)$, were used. To take into account the hydration effects, a purely implicit approach by placing the solute in a cavity within the solvent reaction field was taken into consideration. This hydration model is based on the so-called integral equation formalism variant of the polarizable continuum model (IEFPCM). ${ }^{52,53}$ The relative permittivity of the solvent continuum was supposed to be that of water, i.e. $\varepsilon_{\mathrm{r}}=78.39$. Final energetic analysis of optimized conformers was based on the electronic energy $\left(E_{\mathrm{e}}\right)$. Each optimized geometry was characterized by its relative energy $(\Delta E)$ with respect to the lowest energy one, referred to as $\Delta E=0$. Quantum mechanical calculations were carried out by means of the Gaussian09 package. ${ }^{54}$

\section{Conclusion}

Based on the spectroscopic evidence, we have shown here that octreotide and pasireotide present different structural features in an aqueous environment. Precisely, while octreotide adopts a moderately flexible backbone and disulfide linkage, pasireotide manifests a rigid structure including two oppositely placed tight folds in its cyclic part.

Because of their cationic character, both peptides bind to the surfaces of negatively charged plasmonic colloids, inducing the aggregation of large size $(\sim 95 \mathrm{~nm})$ gold and polydisperse silver particles. It has been shown that the largest plasmonic redshift observed in the UV-visible absorption spectra of AuNPs could be achieved at $10^{-7} \mathrm{M}\left(\sim 0.1 \mu \mathrm{g} \mathrm{ml}{ }^{-1}\right)$ peptide concentration. In the case of AgNPs, a higher peptide concentration, i.e. $10^{-6} \mathrm{M}\left(\sim 1 \mu \mathrm{g} \mathrm{ml} \mathrm{m}^{-1}\right)$ for pasireotide, and $10^{-5} \mathrm{M}\left(\sim 10 \mu \mathrm{g} \mathrm{ml}^{-1}\right)$ for octreotide, was required to induce the largest plasmonic redshifts. This can be explained by the lower electrostatic potential of silver nanoparticles, compared to that of AuNPs. Despite their manifest structural differences, both SST analogues have shown their preference to bind to gold particles through their unique D-Trp residue. Peptide binding to the gold surface is certainly facilitated by the high rotational freedom of the D-Trp residue. SERS could also provide evidence on different binding schemes of SST analogues on AgNPs, through the formation of ionic pairs (of $\mathrm{Cl}^{-} \rightarrow \mathrm{NH}_{3}{ }^{+}$type), between the chloride ions covering the silver surfaces and the cationic groups of each peptide.

The information obtained on the structural features of the analyzed SST analogues in an aqueous environment will certainly help to better understand their binding mechanisms to SSTRs. Beyond this fact, this work should also be considered as an initial stage in the development of functionalized plasmonic NPs by SST analogues. In this framework, the recognition of the preferential anchoring sites of octreotide and pasireotide would be of key importance for the choice of the molecular groups to be attached to the metal surface in order to optimize the binding of SST analogues to SSTRs. To get closer to physiological conditions we have performed additional experiments by increasing $\mathrm{pH}$ and ionic strength (not shown). The collected data are consistent with the fact that the mentioned environmental parameters can compensate each other, rendering possible the adsorption of the peptides, as well as the aggregation of gold particles. Nevertheless, we are conscious that in biological fluids, 
the functionalized AuNPs with SST analogues will be subjected to the formation of protein corona. ${ }^{5-58}$ To minimize this effect a number of polymer-coated NPs were elaborated. ${ }^{57}$ Special attention is also to be paid to the time evolution and biocompatibility of the functionalized NPs. ${ }^{55,57,59}$

\section{Acknowledgements}

The authors would like to thank Novartis Pharma (Basel, Switzerland) for generously providing the lyophilized sample of pasireotide. This work was granted access to the HPC resources of IDRIS (Orsay, France) under the allocations c2016085065 by GENCI (Grand Equipement National de Calcul Intensif). A. C. was supported by a Pasteur Innov (PIV15-197) and a PTR grant (PTR451) from Institut Pasteur. S. S. C. acknowledges the Spanish Ministerio de Economia y Competitividad for the project FIS2014-52212-R.

\section{References}

1 M. C. De Martino, L. J. Hofland and S. W. Lamberts, Somatostatin and somatostatin receptors: from basic concepts to clinical applications, Prog. Brain Res., 2010, 182, 255-280.

2 C. Bruns, I. Lewis, U. Briner, G. Meno-Tetang and G. Weckbecker, SOM230: A novel Somatostatin peptidomimetic with broad somatotropin release inhibiting factor (SRIF) receptor binding and a unique antisecretory profile, Eur. J. Endocrinol., 2002, 146, 707-716.

3 G. Weckbecker, I. Lewis, R. Albert, H. A. Schmid, D. Hoyer and C. Bruns, Opportunities in somatostatin research: biological, chemical and therapeutic aspects, Nat. Rev. Drug Discovery, 2003, 2, 999-1017.

4 W. Vale, G. Grant, M. Amoss, R. Blackwell and R. Guillemin, Culture of enzymatically dispersed pituitary cells: functional validation of a method, Endocrinology, 1972, 91, 562-572.

5 M. Brown, J. Rivier and W. Vale, Biological activity of somatostatin and somatostatin analogs on inhibtion of arginine-induced insulin and glucagon release in the rat, Endocrinology, 1976, 98, 336-343.

6 G. Interlandi, Backbone conformations and side chain flexibility of two somatostatin mimics investigated by molecular dynamics simulations, Proteins, 2009, 75, 659-670.

7 E. Pohl, A. Heine, G. M. Sheldrick, Z. Dauter, K. S. Wilson, J. Kallen, W. Huber and P. J. Pfäffli, Structure of octreotide, a somatostatin analogue, Acta Crystallogr., Sect. D: Biol. Crystallogr., 1995, 51, 48-59.

8 G. Melacini, Q. Zhu and M. Goodman, Multiconformational NMR analysis of sandostatin (octreotide): equilibrium between $\beta$-Sheet and partially helical structures, Biochemistry, 1997, 36, 1233-1241.

9 H. Widmer, A. Widmer and W. J. Braunn, Extensive distance geometry calculations with different noe calibrations-new criteria for structure selection applied to sandostatin and BPTI, J. Biomol. NMR, 1993, 3, 307-324.
10 B. Hernández, Y. M. Coïc, S. G. Kruglik, C. Carelli, R. Cohen and M. Ghomi, Octreotide used for probing the type-II $\beta$-turn CD and Raman markers, J. Phys. Chem. B, 2012, 116, 9337-9345.

11 I. L. Lewis, R. Albert, W. Bauer, N. Chandramouli, J. Pless, L. Oberer, G. Bovermann, J. van der Hoek, V. Boerlin, S. W. J. Lamberts, H. A. Schmid, G. Weckbecker and C. Bruns, The superior therapeutic properties of som 230 originate from unique structural elements, Chimia, 2004, 58, 222-227.

12 K. S. Lee and M. A. El-Sayed, Gold and silver nanoparticles in sensing and imaging: sensitivity of plasmon response to size, shape, and metal composition, J. Phys. Chem. B, 2006, 110, 19220-19225.

13 M. A. Shenashen, S. A. El-Safty and E. A. Elshehy, Synthesis, morphological control, and properties of silver nanoparticles in potential applications, Part. Part. Syst. Charact., 2014, 31, 293-316.

14 P. K. Jain, I. H. El-Sayed and M. A. El-Sayed, Au nanoparticles target cancer, Nano Today, 2007, 2, 18-29.

15 Y. Li, C. Jing, L. Zhang and Y. T. Long, Resonance scattering particles as biological nanosensors in vitro and in vivo, Chem. Soc. Rev., 2012, 41, 632-642.

16 R. Qian, Y. Cao and Y. T. Long, Dual-targeting nanovesicles for in situ intracellular imaging of and discrimination between wild-type and mutant p53, Angew. Chem., Int. Ed., 2016, 55, 719-723.

17 A. N. Kharlamov, A. E. Tyurnina, V. S. Veselova, O. P. Kovtun, V. Y. Shur and J. L. Gabinsky, Silica-gold nanoparticles for atheroprotective management of plaques: results of the NANOM-FIM trial, Nanoscale, 2015, 7, 8003-8015.

18 M. Karimi, H. Zare, A. Bakhshian Nik, N. Yazdani, M. Hamrang, E. Mohamed, P. Sahandi Zangabad, S. M. Moosavi Basri, L. Bakhtiari and M. R. Hamblin, Nanotechnology in diagnosis and treatment of coronary artery disease, Nanomedicine, 2016, 11, 513-530.

19 A. Majzik, L. Fülöp, E. Csapó, F. Bogár, T. Martinek, B. Penke, G. Bíró and I. Dékány, Functionalization of gold nanoparticles with amino acid, $\beta$-amyloid peptides and fragment, Colloids Surf., B, 2010, 81, 235-241.

20 A. A. Abdellatif, G. Zayed, A. El-Bakry, A. Zaky, I. Y. Saleem and H. M. Tawfeek, Novel gold nanoparticles coated with somatostatin as a potential delivery system for targeting somatostatin receptors, Drug Dev. Ind. Pharm., 2016, DOI: 10.3109/03639045.2016.1173052.

21 H. Mendoza-Nava, G. Ferro-Flores, B. Ocampo-García, J. Serment-Guerrero, C. Santos-Cuevas, N. Jiménez-Mancilla, M. Luna-Gutiérrez and M. A. Camacho-López, Laser heating of gold nanospheres functionalized with octreotide: in vitro effect on HeLa cell viability, Photomed. Laser Surg., 2013, 31, 17-22.

22 J. Chen, W. Ding, Z. Luo, B. H. Loo and J. Yao, Probing single molecules and molecular aggregates: Raman spectroscopic advances, J. Raman Spectrosc., 2015, DOI: 10.1002/ jrs.4866.

23 L. Guerrini, I. Izquierdo-Lorenzo, J. V. Garcia-Ramos, C. Domingo and S. Sanchez-Cortes, Self-assembly of 
$\alpha, \omega$-aliphatic diamines on $\mathrm{Ag}$ nanoparticles as an effective localized surface plasmon nanosensor based in interparticle hot spots, Phys. Chem. Chem. Phys., 2009, 11, 7363-7371.

24 K. Gunasekaran, C. Ramakrishnan and P. Balaram, Betahairpins in proteins revisited: lessons for de novo design, Protein Eng., 1997, 10, 1131-1141.

25 E. Pohl, A. Heine, G. M. Sheldrick, Z. Dauter, K. S. Wilson, J. Kallen, W. Huber and P. J. Pfäffli, Structure of octreotide, a somatostatin analogue, Acta Crystallogr., 1995, D51, 48-59.

26 NMR Study of the backbone conformational equilibria of sandostatin, minimized average beta-sheet structure, PDB ID:1SOC, http://www.rcsb.org/pdb/explore.do?structureId=1soc.

27 B. Hernández, Y. M. Coïc, B. Baron, S. G. Kruglik, F. Pflüger, R. Cohen, C. Carelli and M. Ghomi, Low concentration structural dynamics in lanreotide and somatostatin-14, Biopolymers, 2014, 101, 1019-1028.

28 A. Perczel and G. D. Fasman, Quantitative analysis of cyclic $\beta$-turn models, Protein Sci., 1992, 1, 378-395.

29 S. M. Kelly and N. C. Price, The use of circular dichroism in the investigation of protein structure and function, Curr. Protein Pept. Sci., 2000, 1, 349-384.

30 P. F. Fuchs, A. M. Bonvin, B. Bochicchio, A. Pepe, A. J. Alix and A. M. Tamburro, Kinetics and thermodynamics of type VIII beta-turn formation: a CD, NMR, and microsecond explicit molecular dynamics study of the GDNP tetrapeptide, Biophys. J., 2006, 90, 2745-2759.

31 R. Mahalakshimi, G. Shanmugam, P. L. Polavarapu and P. Balaram, Circular dichroism of designed peptide helices and $\beta$-hairpins: analysis of Trp- and Tyr-rich peptides, ChemBioChem, 2005, 6, 2152-2158.

32 P. Bour, J. Kim, J. Kapitan, R. P. Hammer, R. Huang, L. Wu and T. Keiderling, Vibrational circular dichroism and IR spectral analysis as a test of theoretical conformational modelling for a cyclic hexapeptide, Chirality, 2008, 20, 1104-1119.

33 B. Hernández, F. Pflüger, E. López-Tobar, S. G. Kruglik, J. V. Garcia-Ramos, S. Sanchez-Cortes and M. Ghomi, Disulfide Linkage Raman Markers: A Reconsideration Attempt, J. Raman Spectrosc., 2014, 45, 657-664.

34 A. Motta, M. R. Reches, L. Pappalardo, G. Andretti and E. Gazit, The preferred conformation of tripeptide Ala-Phe-Ala in water is an inverse $\gamma$-turn: implications for protein folding and drug design, Biochemistry, 2005, 44, 14170-14178.

35 E. J. Milner-White, B. M. Ross, R. Ismail, K. Belhadj-Mostefa and R. Poet, One type of gamma-turn, rather than the other gives rise to chain-reversal in proteins, J. Mol. Biol., 1988, 204, 777-782.

36 J. A. Drewes and K. L. Rowlen, Evidence for a $\gamma$-turn motif in antifreeze glycopeptides, Biophys. J., 1993, 65, 985-991.

37 K. Uray, J. Kajtár, E. Vass, M. R. Price, M. Hollósi and F. Hudecz, Effect of D-amino acid substitution in mucinspecific monoclonal antibody recognition, Arch. Biochem. Biophys., 2000, 378, 25-32.

38 E. López-Tobar, B. Hernández, A. Chenal, Y. M. Coïc, J. Gómez Santos, E. Mejía-Ospino, J. V. Garcia-Ramos, M. Ghomi and S. Sanchez-Cortes, Large size citrate-reduced gold colloids appear as optimal SERS substrates for cationic peptides, J. Raman Spectrosc., 2016, DOI: 10.1002/jrs.4976.

39 E. López-Tobar, B. Hernández, J. Gómez, A. Chenal, J. V. Garcia-Ramos, M. Ghomi and S. Sanchez-Cortes, Anchoring Sites of Fibrillogenic Peptide Hormone Somatostatin-14 on Plasmonic Nanoparticles, J. Phys. Chem. C, 2015, 119, 8273-8279.

40 B. Hernández, F. Pflüger, A. Adenier, S. G. Kruglik and M. Ghomi, Vibrational analysis of amino acids and short peptides in hydrated media. VIII. Amino Acids with aromatic side chains: L-phenylalanine, L-tyrosine, and L-tryptophan, J. Phys. Chem. B, 2010, 114, 15319-15330.

41 F. Pflüger, B. Hernández and M. Ghomi, Vibrational analysis of amino acids and short peptides in hydrated media. VII. Energy landscapes, energetic and geometrical features of L-histidine with protonated and neutral side chains, J. Phys. Chem. B, 2010, 114, 9072-9083.

42 B. Hernández, F. Pflüger, S. G. Kruglik and M. Ghomi, Characteristic Raman lines of phenylalanine analyzed by a multiconformational analysis, J. Raman Spectrosc., 2013, 44, 827-833.

43 B. Hernández, Y. M. Coïc, F. Pflüger, S. G. Kruglik and M. Ghomi, All characteristic Raman markers of tyrosine and tyrosinate originate from phenol ring fundamental vibrations, J. Raman Spectrosc., 2016, 47, 210-220.

44 J. Turkevich, J. Hillier and P. C. Stevenson, A study of the nucleation and growth processes in the synthesis of colloidal gold, Discuss. Faraday Soc., 1951, 11, 55-57.

45 G. Frens, Controlled nucleation for the regulation of the particle size in monodisperse gold suspensions, Nature, 1973, 241, 20-22.

46 A. C. Sotomayor-Pérez, D. Ladant and A. Chenal, Calciuminduced folding of intrinsically disordered repeat-in-toxin (RTX) motifs via changes of protein charges and oligomerization states, J. Biol. Chem., 2011, 286, 16997-17004.

47 A. C. Sotomayor-Pérez, J. C. Karst, D. Ladant and A. Chenal, Mean net charge of intrinsically disordered proteins: experimental determination of protein valence by electrophoretic mobility measurements, Methods Mol. Biol., 2012, 896, 331-349.

48 J. R. Lackowicz, Principles of fluorescence spectroscopy, Springer, New York, 3rd edn, 2006, pp. 353-364.

49 W. Kohn and L. J. Sham, Self-consistent equations including exchange and correlation effects, Phys. Rev., 1965, 140, A1133-A1138.

50 C. Lee, W. Yang and R. G. Parr, Development of the Colle-Salvetti correlation-energy formula into a functional of the electron density, Phys. Rev. B: Condens. Matter Mater. Phys., 1988, 37, 785-789.

51 A. D. Becke, Density-functional thermochemistry. III. The role of exact exchange, J. Chem. Phys., 1993, 98, 5648-5652.

52 V. Barone and M. Cossi, Quantum calculation of molecular energies and energy gradients in solution by a conductor solvent model, J. Phys. Chem. A, 1988, 102, 1995-2001.

53 M. Cossi, N. Rega, G. Scalmani and V. Barone, Energies, structures, and electronic properties of molecules in 
solution with the C-PCM solvation model, J. Comput. Chem., 2003, 24, 669-681.

54 M. J. Frisch, G. W. Trucks, H. B. Schlegel, G. E. Scuseria, M. A. Robb, J. R. Cheeseman, G. Scalmani, V. Barone, B. Mennucci, G. A. Petersson, H. Nakatsuji, M. Caricato, X. Li, H. P. Hratchian, A. F. Izmaylov, J. Bloino, G. Zheng, J. L. Sonnenberg, M. Hada, M. Ehara, K. Toyota, R. Fukuda, J. Hasegawa, M. Ishida, T. Nakajima, Y. Honda, O. Kitao, H. Nakai, T. Vreven, J. A. Montgomery Jr., J. E. Peralta, F. Ogliaro, M. Bearpark, J. J. Heyd, E. Brothers, K. N. Kudin, V. N. Staroverov, T. Keith, R. Kobayashi, J. Normand, K. Raghavachari, A. Rendell, J. C. Burant, S. S. Iyengar, J. Tomasi, M. Cossi, N. Rega, J. M. Millam, M. Klene, J. E. Knox, J. B. Cross, V. Bakken, C. Adamo, J. Jaramillo, R. Gomperts, R. E. Stratmann, O. Yazyev, A. J. Austin, R. Cammi, C. Pomelli, J. W. Ochterski, R. L. Martin, K. Morokuma, V. G. Zakrzewski, G. A. Voth, P. Salvador, J. J. Dannenberg, S. Dapprich, A. D. Daniels, O. Farkas, J. B. Foresman, J. V. Ortiz, J. Cioslowski and D. J. Fox, Gaussian, Inc., Wallingford CT, 2013.
55 E. Casals, T. Pfaller, A. Duschl, G. J. Oostingh and V. Puntes, Time evolution of the nanoparticle protein corona, ACS Nano, 2010, 4, 3623-3632.

56 C. D. Walkey, J. B. Olsen, F. Song, R. Liu, H. Guo, D. W. H. Olsen, Y. Cohen, A. Emili and W. C. W. Chan, Protein corona fingerprinting predicts the cellular interaction of gold and silver nanoparticles, ACS Nano, 2014, 8, 2439-2455.

57 B. Pelaz, P. del Pino, P. Maffre, R. Hartmann, M. Gallego, S. Rivera-Fernández, J. M. de la Fuente, G. Ulrich Nienhaus and W. J. Parak, Surface functionalization of nanoparticles with polyethyleneglycol: effects on protein adsorption and cellular uptake, ACS Nano, 2015, 9, 6996-7008.

58 S. Khan, A. Gupta and C. K. Nandi, Controlling the fate of protein corona by tuning surface properties of nanoparticles, J. Phys. Chem. Lett., 2013, 4, 3747-3752.

59 S. J. Soenen, B. Manshian, J. M. Montenegro, F. Amin, B. Meermann, T. Thiron, M. Cornelissen, F. Vanhaecke, S. Doak, W. J. Parak, S. De Smedt and K. Braeckmans, Cytotoxic effects of gold nanoparticles: a multiparametric study, ACS Nano, 2012, 6, 5767-5783. 